\title{
The human intestinal B-cell response
}

\author{
J Spencer ${ }^{1,3}$ and LM Sollid ${ }^{2,3}$
}

The intestinal immune system is chronically challenged by a huge plethora of antigens derived from the lumen. B-cell responses in organized gut-associated lymphoid tissues and regional lymph nodes that are driven chronically by gut antigens generate the largest population of antibody-producing cells in the body: the gut lamina propria plasma cells. Although animal studies have provided insights into mechanisms that underpin this dynamic process, some very fundamental differences in this system appear to exist between species. Importantly, this prevents extrapolation from mice to humans to inform translational research questions. Therefore, in this review we will describe the structures and mechanisms involved in the propagation, dissemination, and regulation of this immense plasma cell population in man. Uniquely, we will seek our evidence exclusively from studies of human cells and tissues.

\section{INTRODUCTION}

Immune protection of the human intestinal mucosa depends on the secretion of IgA by plasma cells that occupy the diffuse subepithelial connective tissue of the intestinal lamina propria. Locally secreted immunoglobulin A (IgA) bound to polymeric Ig receptor (pIgR) is actively transported into the gut lumen where it regulates bacterial populations. ${ }^{1,2}$ The body commits considerable resources to the production of intestinal IgA. The number of IgA-producing plasma cells, at approximately $6 \times 10^{10}$, exceeds the total number of plasma cells in the rest of the body combined, including bone marrow, lymph nodes, and spleen. ${ }^{1,3}$ Intestinal plasma cells secrete between 3 and $5 \mathrm{~g}$ of IgA per day that is actively transported into the gut lumen to provide continuous protection of the mucosal barrier. Human intestinal $\operatorname{IgA}$ is mostly dimeric and comprises both the IgA1 and IgA2 subclass. The ratio between plasma cells secreting the two subclasses of IgA is not the same through the gastrointestinal tract. Whereas most plasma cells in the small intestine secrete IgA1, the proportion of IgA2 increases from the duodenum through to the terminal ileum and the subclasses are present in approximately equal numbers in the colon (Figure 1). IgA2 has a shorter hinge than IgA1 and as a consequence is less susceptible to bacterial proteases and would therefore have a functional advantage in the lumen of the colon that is rich in bacterial species. In contrast, while IgA is the second most common Ig isotype in blood after IgG, most IgA in serum is monomeric IgA $1 .{ }^{1}$
The precursors of lamina propria IgA plasma cells are generated in microanatomically discrete zones of organized lymphoid inductive sites, such as the gut-associated lymphoid tissue (GALT) and gut regional lymph nodes (Figure 1). First we will consider the structure and function of human GALT and then the derivation and unique properties of intestinal plasma cells themselves.

\section{B CELLS IN GALT}

Most of the intestine is structured to prevent the entry of potentially pathogenic material into the body, for example, by epithelial tight junctions to maintain the integrity of the monolayer even through rapid cell turnover and the production of antimicrobial peptides, such as defensins. ${ }^{4,5}$ In contrast, GALT is associated with an epithelial structure that facilitates antigen entry (Figure 1). Antigens may be sampled by epithelial cells termed microfold (M) cells that comprise part of the specialized follicle-associated epithelium (FAE). ${ }^{6}$ GALT covered by an FAE may be located anywhere through the gastrointestinal tract but tends to be concentrated in the terminal ileum and the appendix. ${ }^{7}$ In these locations, GALT comprises lymphoid follicles that tend to be located on the mucosal aspect of the muscularis mucosae with a broad and relatively exposed FAE. ${ }^{8}$ In the colon, most of the lymphoid tissue tends to be concentrated on the serosal side of the muscularis layer, protruding through a hole in the

${ }_{1}^{1}$ Peter Gorer Department of Immunobiology, King's College London, London, UK and ${ }^{2}$ Centre for Immune Regulation and Department of Immunology, University of Oslo and Oslo University Hospital-Rikshospitalet, Oslo, Norway. Correspondence: J Spencer or LM Sollid (jo.spencer@kcl.ac.uk or I.m.sollid@medisin.uio.no)

${ }^{3}$ These authors contributed equally to this work. 


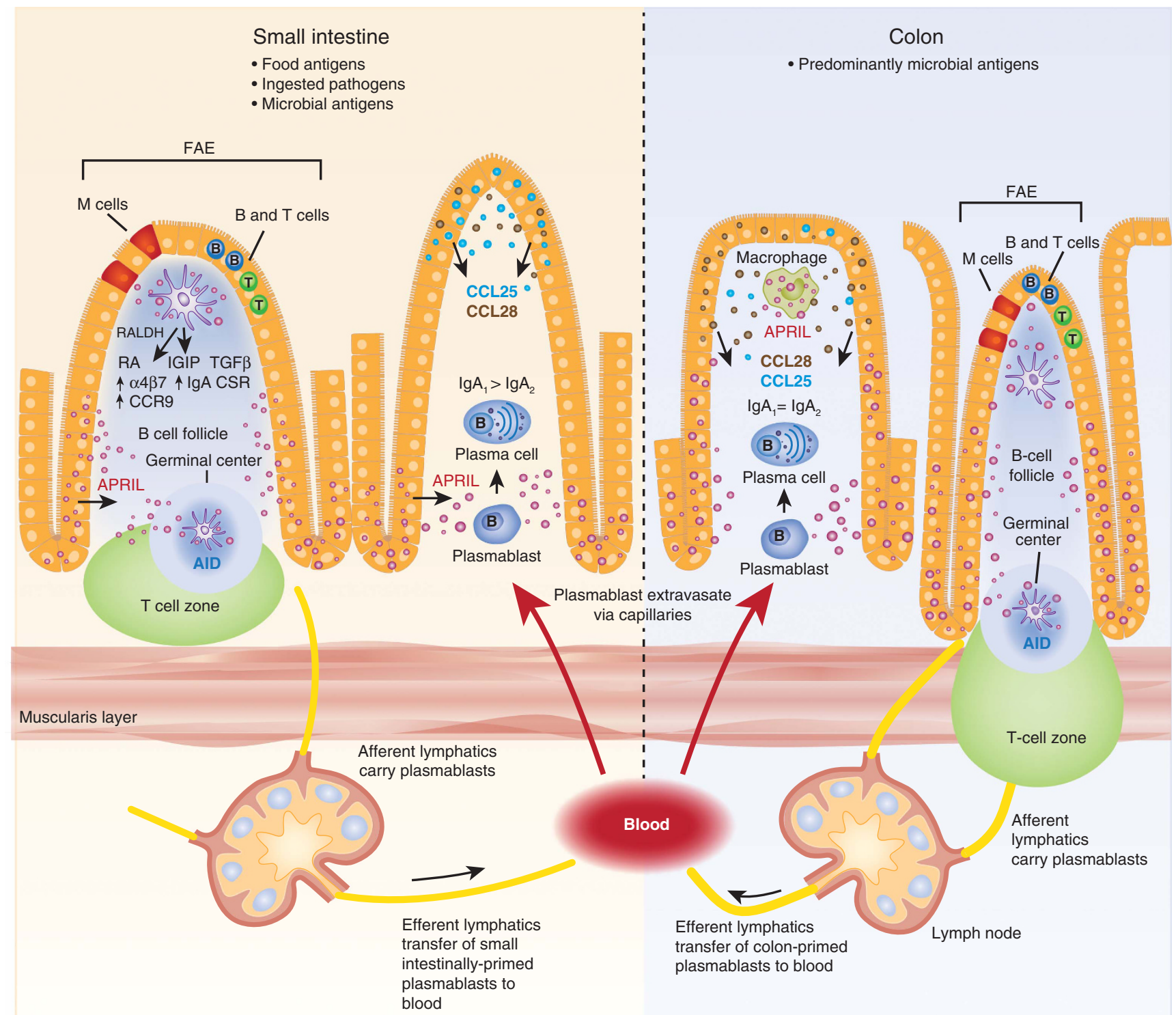

Figure 1 Immune responses in the intestine are initiated in gut-associated lymphoid tissue (GALT) and in gut regional lymph nodes. Whereas food and ingested antigens are present in the small bowel, microbial antigens represent a major immune challenge in the colon. Antigens at both gut locations are sampled by follicle-associated epithelium (FAE). Dendritic cells in the subepithelial area are key regulators of the fate of responding B cells. They express the enzyme retinaldehyde dehydrogenase that catalyzes the production of retinoic acid that subsequently imprints homing via the induction of $\alpha 4 \beta 7$ and C-C motif receptor 9 (CCR9). They also secrete immunoglobulin A (IgA)-inducing protein (IGIP) and APRIL (a proliferation-inducing ligand) that together with stromally derived transforming growth factor- $\beta$ (TGF $\beta$ ) support IgA class switch recombination. Following clonal expansion, hypermutation and selection in the germinal centers of Peyer's patches or regional lymph nodes, plasmablasts enter the blood, via the lymphatic system. Plasmablasts subsequently home back to the lamina propria where they differentiate into plasma cells. The chemokines C-C motif chemokine ligand 25 (CCL25) and CCL28 may contribute to the differential homing of plasmablasts primed in the small intestine or colon, though how and where the lymphocyte receptor of CCL28, CCR10, is induced is not known.

muscularis and forming a narrow FAE interface with the lumen. ${ }^{9}$

The FAE interacts intimately with the lymphoid tissue below and is infiltrated by lymphocytes, including B cells, from approximately 20 weeks of gestation onwards. ${ }^{10,11}$ The amount of lymphoid tissue present in the gut increases through the last 20 weeks of gestation, with acquisition accelerating after birth and continuing to increase through to 12 years of age, after which the number of lymphoid follicles declines so that their frequency reaches levels present at birth in the eighth decade. ${ }^{12}$

GALT contains diverse B-cell subsets. The central feature of most GALT in the small intestine and appendix are the prominent germinal centers (GCs) containing B cells that have been activated. B cells in GCs are surrounded by other cells, such as follicle dendritic cells, $\mathrm{T}$ follicular helper cells, and 

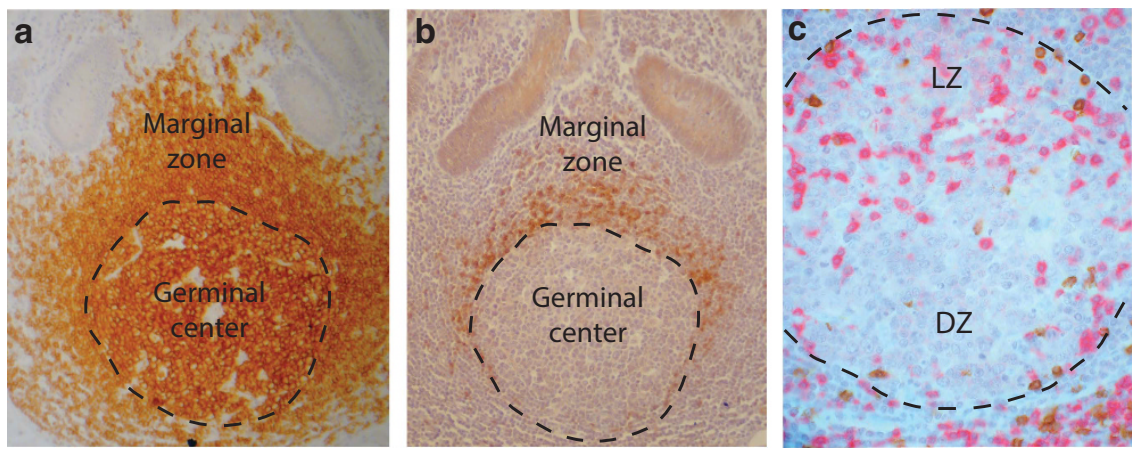

Figure 2 Paraffin sections of gut-associated lymphoid tissue (GALT) in human colon stained for (a) CD20 (brown), (b) IgD (brown) and (c) CD3 (pink) and CD8 (brown). Nuclei are counterstained blue. The germinal center (GC) is surrounded by a dashed circle. Highly immunoglobulin D (IgD) expressing naive $B$ cells in $\mathbf{b}$ surround the GC, forming a relatively sparse mantle zone. The more extensive marginal zone $B$-cell population extends between the mantle zone and the follicle-associated epithelium (FAE). T cells in GALT are mostly CD4 ${ }^{+}$cells. T follicular helper cells defined by their location in the GC are rarely $\mathrm{CD}^{+}$and are located predominantly in the light zone (LZ) of the GC where they are involved in repertoire selection. T cells are rarely present in the dark zone (DZ).

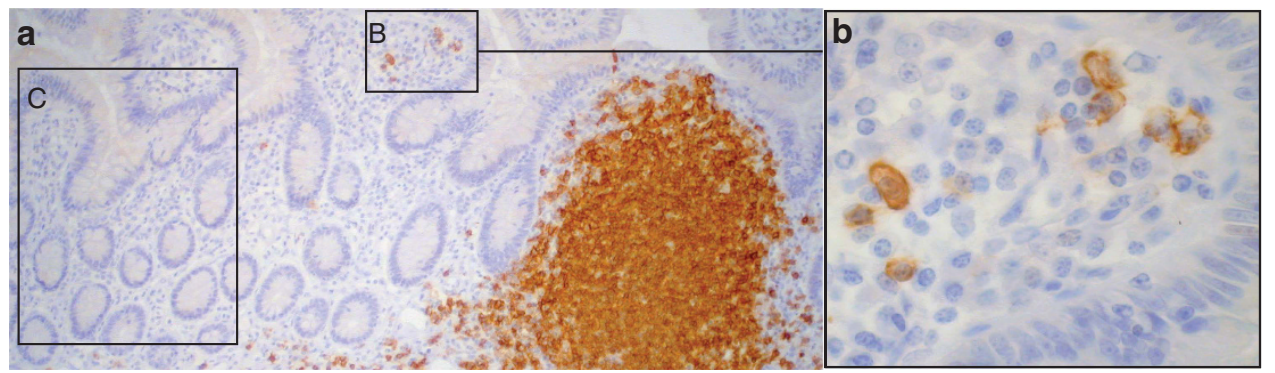

Figure 3 Paraffin section of human ileum stained with CD20 (brown). Nuclei are counterstained in blue. CD20 expressing B cells are abundant in gut-associated lymphoid tissue (GALT). The lamina propria adjacent to GALT may contain B cells that tend to be large cells resembling plasmablasts or plasma cells (identified with a box in (a) and magnified in panel (b)). Distant lamina propria, however, contains few, if any, CD20 ${ }^{+}$B cells (box (C)).

tingible body macrophages that support GC B-cell clonal expansion and selection (Figure 2). The ubiquitous presence of a GC in small intestinal GALT is likely a reflection of the chronic stimulation by antigens derived from the lumen via the FAE and the high antigen load. Pockets of cells that have features of GC B cells have been described in FAE, ${ }^{13}$ suggesting unique features of B-cell responses with FAE location. Colonic GALT less consistently contains a GC though the likelihood of the presence of GC in colonic GALT is increased by the presence of a colonic tumor. ${ }^{9}$

The GC is surrounded by a mantle zone of $\mathrm{CD} 27^{-} \operatorname{IgM}^{+}$ $\mathrm{IgD}^{+}$mature naive $\mathrm{B}$ cells that is generally sparse in GALT compared with the tonsil or a lymph node. The mantle has its broadest aspect facing the direction of antigen entry: either the FAE of GALT or the subcapsular sinus of lymph node. The mantle zone of GALT is surrounded by a marginal zone of $\mathrm{B}$ cells that lack the strong expression of $\mathrm{IgD}$ of mantle zone cells and that extends to and infiltrates the adjacent FAE. ${ }^{11}$ The GALT marginal zone $\mathrm{B}$ cells are considered to be the benign analog of the malignant $\mathrm{B}$ cells in marginal zone B-cell lymphoma of mucosa-associated lymphoid tissue (MALT) (MALT lymphoma). ${ }^{14}$ Normal FAE retains a tight structure despite mild disruption by infiltrating lymphocytes. In contrast, the lymphoepithelium formed by MALT lymphoma is a destructive lesion that is pathognomonic of the tumor. ${ }^{14}$

\section{B CELLS OUTSIDE GALT IN THE LAMINA PROPRIA}

Whereas $\mathrm{CD} 20^{+} \mathrm{B}$ cells are numerous in GALT structures, they are scarce in the lamina propria (Figure 3). A few scattered $\mathrm{B}$ cells $\left(\mathrm{CD} 20^{+}, \mathrm{CD} 27^{+}, \mathrm{MHCII}^{+}\right)$, mainly IgA expressing, can be observed in sections of jejunal tissue. This is in contrast to what is observed by flow cytometric analysis of single-cell suspension made from resection specimens. In this case, numerous $\mathrm{B}$ cells, including $\operatorname{sIgD}^{+}$naive $\mathrm{B}$ cells, can be observed. Thus contamination of cells from GALT structures is an important confounder in analysis of single-cell suspension of mucosal tissue samples. B lineage effector cells secreting antibodies, i.e., plasma cells and plasmablasts, have an almost exclusive distribution in the gut in the lamina propria. ${ }^{15} \operatorname{IgA}$ is by far the dominant isotype produced by these cells. In duodenum/jejunum, 79\% of plasma cells express IgA, 18\% express IgM, and $3 \%$ express IgG, whereas the corresponding numbers in the colon are 90,6 and 4\%. ${ }^{1}$ In the small intestine, most of the plasma cells are localized in a zone stretching from the luminal $100 \mu \mathrm{m}$ of the crypt layer to the basal $100 \mu \mathrm{m}$ of the villi, a zone intermingled with a few T cells. ${ }^{1}$ Initial observations by Farstad et al. ${ }^{15}$ reported that some IgA immunocytes express 


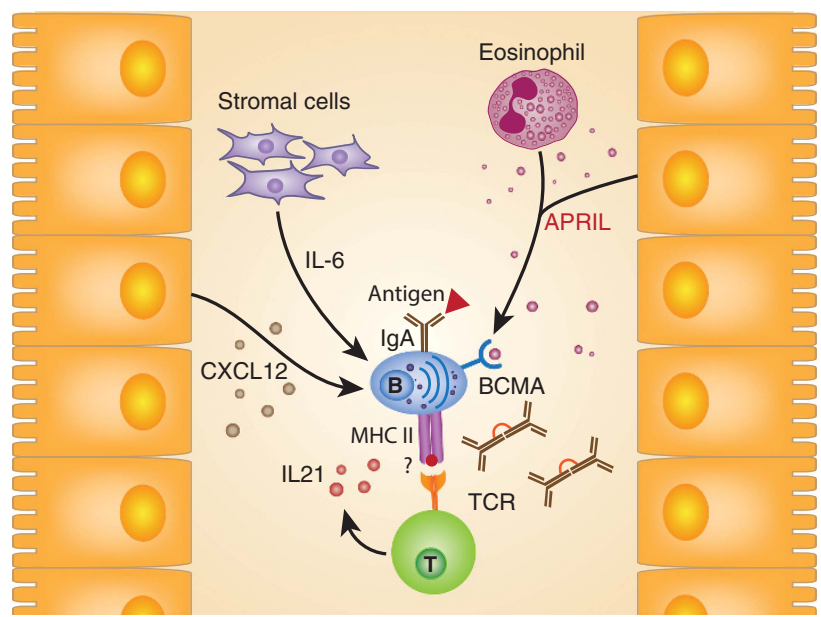

Figure 4 Illustration of factors that support plasma cells that can bind antigen through their B-cell receptor in the lamina propria niche. Stromal cell-derived interleukin (IL)-6 may bind to plasma cell IL-6 receptor and APRIL (a proliferation-inducing ligand) produced by epithelial cells, macrophages, or eosinophils may bind to BCMA on plasma cells to support plasma cell survival. C-X-C motif chemokine ligand 12 (CXCL12) may promote plasma cell retention and survival through binding $\mathrm{C}-\mathrm{X}-\mathrm{C}$ motif chemokine receptor 4 (CXCR4). Plasma cell frequencies in the intestine may also be regulated by $T$ cells through the presentation of cognate antigen to local T-cell populations.

surface Ig, and it was suggested that these antibody-secreting cells (ASCs) represent recently arrived plasmablasts. Benkert et al. ${ }^{16}$ also termed these cells plasmablasts as the authors found, similar to what had been observed by Di Niro et al., ${ }^{17}$ that virtually all gut IgA and IgM ASCs express surface Ig. Notwithstanding, these cells generally lack intracellular expression of proliferation-associated protein Ki-67 and express CD138, indicating that they are plasma cells rather than plasmablasts. ${ }^{17}$ Further in support of the notion that these are not plasmablasts captured in narrow window of differentiation, it was observed that surface Ig is maintained on ASCs in culture of gut biopsies even after 4 weeks. ${ }^{18}$ The expression of surface IgA and IgM is not unique to gut ASCs as this feature is also observed in plasma cells of the bone marrow. ${ }^{19}$ In fact, the surface Ig of IgA and IgM plasma cells appears to be a functional $\mathrm{B}$-cell receptor that is associated with $\operatorname{Ig} \alpha / \operatorname{Ig} \beta$. Consistent with this, crosslinking of IgA and IgM on the surface of plasma cells gives $\mathrm{Ca}^{2+}$ mobilization and extracellular signal-regulated kinase 1/2 and AKT phosphorylation. B-cell receptor crosslinking furthermore leads to increased survival of IgA plasma cells as measured by intact Ig secretion after 4 days. ${ }^{19}$ In contrast to IgG plasma cells that are located at sites (bone marrow and spleen) mostly devoid of antigen, IgA and IgM plasma cells are primarily located at mucosal sites where they can be in contact with antigen. Thus sensing of antigen by IgA and IgM plasma cells using their surface antigen receptor could help in guiding production of secretory Ig for which there is a need both by stimulating antibody production and by securing cell survival. Plasma cell survival could either happen directly as indicated by Pinto et al. ${ }^{19}$ or indirectly via $\mathrm{T}$ cells owing to antigen presentation (Figure 4). As to the latter, plasma cells have barely detectable major histocompatibility complex (MHC) class II expression. Notwithstanding, if the few MHC class II molecules are loaded with peptides from antigen extremely efficiently taken up by the cell via the B-cell receptor, this could be sufficient to receive T-cell help. The two mechanisms are not mutually exclusive, and further work is needed to determine whether these mechanisms operate in the gut.

High-dimension analysis of B cells in the intestine by singlecell mass cytometry demonstrated that intestinal ASCs generally have low expression of chemokine receptors $\mathrm{C}-\mathrm{C}$ motif receptor 6 (CCR6) and CCR7 and high expression of CCR10 and C-X-C motif chemokine receptor 4 (CXCR4), i.e., they carry the phenotype $\mathrm{CCR}^{\mathrm{lo} /{ }^{-}} \mathrm{CCR} 7^{\mathrm{lo} /-} \mathrm{CCR} 10^{+}$ CXCR $4{ }^{+} .{ }^{20}$ The expression of the adhesion molecule $\alpha 4 \beta 7$ integrin in intestinal ASCs is lower than that of ASCs in blood. Further, intestinal and circulating ASCs express lower levels of surface IgA and CD40 than switched memory B cells, and interestingly, in contrast to circulating ASCs that are HLA-DR ${ }^{+} /{ }^{-} \mathrm{CD} 5^{+}$, intestinal plasma cells are generally HLA-DR ${ }^{-} \mathrm{CD} 95^{-}$. This suggests that the cells would be non-responsive to apoptosis via CD95 ligation. ${ }^{20}$

\section{FUNCTION OF HUMAN GALT}

Precursors of human IgA plasma cells originate from the GC of GALT. Examples of clones of B lineage cells (where clones are identified by the homology of junctional sequences of their rearranged IGHV genes) that are present in both the GC of GALT and also in the lamina propria plasma cell population have been identified. ${ }^{21}$ Probably the best evidence for involvement of the GC in the history of plasma cells in health is the very high frequency of somatic mutations in the rearranged IGHV genes of virtually all human lamina propria plasma cells in health. ${ }^{22}$ The GC is the only place known where somatic mutations are introduced with high frequency into IGV genes. The activation-induced cytidine deaminase (AID) enzyme that catalyzes the mutation of IGV gene segments to generate variable region variants is expressed in the nuclei of centroblasts in GALT GCs and also in the cytoplasm of relatively sparse large interfollicular B cells, the significance of which is not known. ${ }^{23,24}$ The reason that a high frequency of somatic mutation is acquired and tolerated such that on average approximately $8 \%$ of the variable region sequence is changed, despite selective pressure to maintain structural viability, is not known. It may be a consequence of drive from the high antigenic load, the chronicity of the challenge, or lower selective pressure so that a greater range of variants is tolerated.

Despite the apparent ubiquitous involvement of GCs in GALT plasma cell development, it is likely that both T-cell independent type 2 antigens (TI2) that are not conventionally associated with initiation of GC responses and T-cell dependent antigens can both drive B-cell activation in GALT. The gut is rich in bacterial polysaccharide antigens with repeating subunit structures that could potentially initiate TI2 responses. ${ }^{25}$

One of the most distinctive and often unappreciated features of human GALT marginal zone B cells is their expression of Fc 
receptor-like 4 (FCRL4, previously IRTA1 or FCRH4) ${ }^{26}$ that was originally identified by the translocation of the encoding gene to the Ig locus in MALT lymphoma. ${ }^{27}$ This receptor, which does not occur in mice, has immunoreceptor tyrosinebased inhibition motifs and dampens polyclonal immune responses, for example, to B-cell receptor signaling or Staphylococcus aureus Cowan strain. This suggests that the $\mathrm{B}$ cells on the mucosal front line in humans have distinctive raised thresholds of responsiveness. ${ }^{28,29}$ It has also been demonstrated that FCRL4 may detach B-cell responses from the activation signals normally driven through BCR ligation in favor of responses through innate receptors. ${ }^{30}$ In health, FCRL4 expressing B cells are rare in blood and lymphoid tissues distant from epithelia. However, they accumulate systemically in HIV and in individuals from malaria endemic zones. ${ }^{31,32}$ When systemic B cells express FCRL4, this B-cell subset is also refractory to stimulation and has been described as "exhausted". The FCLR4-expressing populations in blood in HIV and malaria tend to be $\mathrm{CD} 27^{-} .31,32$ Interestingly, FCRL4 $^{+}$cells with proinflammatory properties are present in rheumatoid synovium, suggesting functional similarity between $\mathrm{B}$ cells in the gut and the rheumatoid joint. This FCRL4 ${ }^{+}$population is predominantly $\mathrm{IgD}^{-}$and includes $\mathrm{CD} 27^{+}$and $\mathrm{CD} 27^{-}$memory subsets. ${ }^{33}$

The induction of GCs conventionally requires cognate interaction between $\mathrm{B}$ cells and $\mathrm{T}$ cells involving the ligation of CD40 on B cells by CD40L on peptide-primed T cells. The failure of this in X-linked hyper IgM type 1 due to mutations in CD40L results in deficiency in GC formation and dearth of class switched B cells systemically. Class switch to IgA can, however, be retained despite CD40L deficiency. ${ }^{34}$ Studies of blood from patients with CD40L deficiency have identified that $\mathrm{CD} 27^{-} \mathrm{IgA}{ }^{+}$memory $\mathrm{B}$ cells derived in the absence of cognate $\mathrm{T}$-cell help are present in similar frequency to healthy controls, consistent with a T-cell independent pathway for generation of IgA-expressing memory cells. ${ }^{34} \mathrm{CD} 27^{-}$class switched memory $\mathrm{B}$ cells are also increased in relative frequency in patients depleted of T cells by HIV. ${ }^{35}$ Circulating $\mathrm{CD} 27^{-}, \mathrm{IgA}^{+} \mathrm{B}$ cells in health have a bias toward lambda light chain usage, a relatively low frequency of somatic mutations and relatively more polyreactive Igs with a greater tendency to bind bacterial species than $\mathrm{CD}_{2} 7^{+} \mathrm{IgA}^{+}$cells. They also have a gene expression profile suggesting ability to traffic to intestinal sites. $^{34,36}$ Several lines of evidence described above tie a phenotype of $\mathrm{CD} 27^{-}$memory B cells with circumstances of $\mathrm{B}$-cell priming in the absence of cognate T-cell help. Although phenotypic profiles particularly involving CD27 have been proposed to discriminate between $\mathrm{B}$ cells differentiating along T-cell dependent and -independent pathways, others have observed that memory B-cell clones commonly have both $\mathrm{CD} 27^{+}$and $\mathrm{CD} 27^{-}$members. ${ }^{37}$ This will be an interesting area to observe in the future.

\section{IGA CLASS SWITCH RECOMBINATION (CSR)}

The presence of IgA in patients with hyper IgM syndromes suggests that CSR to IgA can be independent of cognate B-cell-
T-cell interactions, ${ }^{34,38}$ though such patients often have small residual GC structures that could potentially support classically GC-dependent processes. ${ }^{39}$

Class switch to IgA requires cell proliferation, induction of the enzymes that mediate the recombination process such as AID, and also switch factors that initiate the production of transcripts from the noncoding switch regions upstream of the Ig $\alpha 1$ and Ig $\alpha 2$ constant region segments (Figure 5). Doublestrand breaks in the switch regions initiated by the deamination of cytidine in the repeating motifs that guide the activity of AID facilitate the exchange of constant region segments in dividing cells. Crosslinking CD40 is a potent stimulator of cell division that can also activate nuclear factor- $\kappa \mathrm{B}$ resulting in upregulation of AID to mediate CSR to all isotypes in the presence of appropriate switch factors. ${ }^{40}$ It has been demonstrated that ligation of TACI (transmembrane activator and calcium modulator and cyclophilin ligand interactor) by APRIL (a proliferation-inducing ligand) can also activate nuclear factor- $\mathrm{\kappa B}$ and induce AID by recruitment of MyD88 to a cytoplasmic domain of TACI. ${ }^{41,42}$ It is also possible that innate ligands such as CpG may drive cell division and CSR in memory cells in the absence of cognate interaction with T cells. $^{25}$

The first switch factor observed to induce IgA CSR through the induction of transcription of $\operatorname{Ig} \alpha$ switch regions was transforming growth factor- $\beta{ }^{43}$ Other cytokines, including interleukin (IL)-10 and IL-4, and retinoic acid have also been implicated in supporting CSR or the maturation of switched B cells. ${ }^{44,45}$ Most recently, IgA-inducing protein (IGIP) produced by dendritic cells, that have previously been implicated in the induction of $\operatorname{IgA} \mathrm{CSR}^{38,46}$ has been demonstrated to induce IgA switching. ${ }^{47}$ The production of IGIP by dendritic cells is regulated by vasoactive peptide. ${ }^{47}$

It is currently unclear how preferential switching to either IgA1 or IgA2 along the intestine is initiated. Recombination to each is usually direct. Despite its downstream location to IgA1, switch to $\operatorname{IgA} 2$ is unlikely to be a second step following an intermediate switch to IgA $1 .{ }^{48}$ Interestingly, higher frequencies of IgA2-secreting cells are observed in locations of high bacterial load, suggesting that preferential switch to IgA2 may be a feature of the inducing antigen. 1,49

During the first month of life, IgA-secreting plasma cells are virtually absent from the intestinal lamina propria. Their subsequent presence increases over the first 2 years of life simultaneous with the expression of APRIL and expression of its receptors TACI and BCMA (B-cell maturation antigen) in GALT. The association between IgA plasma cell appearance and the presence of APRIL and its receptors suggests that this axis is important in plasma cell development in early life. ${ }^{24}$ Epithelial APRIL expression may be modulated by the ligation of Toll-like receptor-5 by flagellin, suggesting that the microbiome could also promote IgA CSR indirectly. ${ }^{41}$

\section{FUNCTION OF SECRETORY ANTIBODIES}

The plasma cells of the gut express the J-chain regardless of the isotype produced. ${ }^{50}$ The J-chain is instrumental to make 

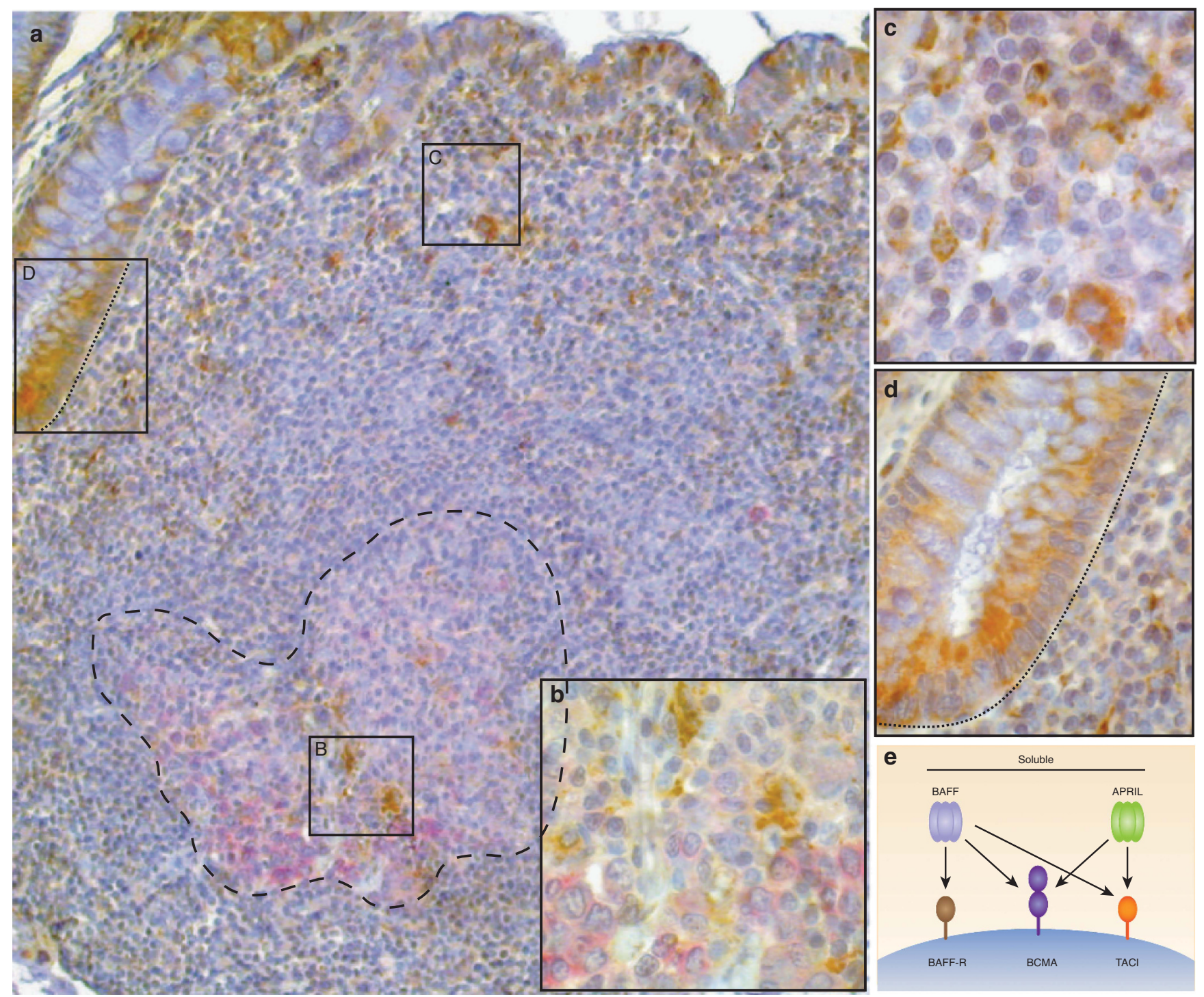

Figure 5 (a) Paraffin section of gut-associated lymphoid tissue (GALT) from the ileum stained for a proliferation-inducing ligand (APRIL; brown) and activation-induced cytidine deaminase (AID; pink). Nuclei are counterstained with hematoxylin (blue). The germinal center (GC) is identified with a dashed line. (b) AID staining is confined to the GC with the exception of occasional large interfollicular B cells that have cytoplasmic AID. APRIL is produced adjacent to B cells expressing AID in the GC. (c) APRIL is abundant in cells with dendritic and macrophage morphology beneath the follicleassociated epithelium (FAE). (d) An area where the crypt epithelium expressing APRIL abuts the lymphoid tissue is indicated with a dotted line. Areas magnified in B-D are identified with labeled boxes in a. (e) The receptors for soluble APRIL and B-cell activating factor (BAFF) are illustrated schematically for reference.

dimeric IgA and pentameric IgM, and it does so by forming covalent disulfide bridges with the $\mathrm{C}$-terminal parts of the $\alpha$ and $\mu$ heavy chains. ${ }^{51-53}$ Polymeric IgA and IgM by means of their J-chain bind to the pIgR that is expressed on the basolateral side of enterocytes. ${ }^{54,55}$ This receptor mediates Ig transport across the epithelium. Secretory antibodies are released by cleavage of the pIgR at the luminal membrane. In the lumen, the released antibodies can bind antigens, including gut microbes, ${ }^{2}$ and thereby mediate immune exclusion and antigen clearance. ${ }^{56}$ Of note, the pIgR can also transport preformed immune complexes ${ }^{57}$ and intracellular dimeric IgA can bind and neutralize lipopolysaccharide thereby having an antiinflammatory role. ${ }^{58}$
The pIgR is not the only receptor for IgA on enterocytes. The transferrin receptor (CD71) also binds $\operatorname{IgA1} .^{59}$ The transferrin receptor is primarily expressed on the apical side of enterocytes, and it can bind and mediate retrotranscytosis of secretory IgA. ${ }^{60}$ This could be a way to facilitate uptake of antigens across the epithelial barrier to which there is an already established humoral response similar to gluten in celiac disease. $^{60}$

\section{FROM GALT TO THE LAMINA PROPRIA VIA THE BLOOD}

Plasmablasts derived from $B$ cells activated in GALT can circulate via the blood and home back to the gut. Homing is mediated by a combination of lymphocyte-homing receptors 
for endothelial ligands such as $\alpha 4 \beta 7$ integrin receptor for mucosal endothelial MAdCAM and chemokine receptors for chemokines secreted by intestinal epithelial cells such as CCR9 and CCR10 that facilitate migration toward C-C motif chemokine ligand 25 (CCL25) and CCL28, respectively. ${ }^{61}$ CCL25 and CCL28 are produced dominantly by the small intestinal and colonic epithelium, respectively, thus providing a mechanism to bias homing of effector cells to either small intestine or colon (Figure 1). $\alpha 4 \beta 7$ and CCR9 are inducible by retinoic acid generated from vitamin A substrate by the RALDH enzyme of GALT dendritic cells. ${ }^{62}$ Vitamin D3 metabolite 1,25-dihydroxyvitamin D3 may induce CCR10 and thus guide migration of plasma cell precursors preferentially to the colon. ${ }^{63}$ Mucosal immunization with cholera toxin, either per oral or rectally generated circulating antibodyforming cells expressing the $\alpha 4 \beta 7$ integrin predominantly. ${ }^{64}$ Similarly, antibody-producing cells generated in response to oral mucosal immunization with salmonella vaccine induced cells in blood that migrated toward chemokines CCL25 and CCL28. ${ }^{65}$

A molecule located in basement membrane surrounding the high endothelial venules (HEV) of GALT but not HEV of peripheral lymph nodes or tonsils has been identified. As lymphocytes traffic through $\mathrm{HEV}$, it is possible that this molecule could be involved in selective recruitment of cells into intestinal tissues. ${ }^{66,67}$

\section{RELATIONSHIP OF B-CELL RESPONSES IN THE GUT TO SYSTEMIC HUMORAL RESPONSES}

In steady state in non-immunized subjects, $80 \%$ of ASCs in peripheral blood express IgA as well as the chemokine receptor CCR 10 and $\alpha 4 \beta 7$ integrin. ${ }^{68}$ This suggests a dominant presence in the blood of ASCs that originate from mucosal immune responses and also these cells should be able to return to mucosal sites, though they were also identified in the bone marrow. Interestingly, upon parenteral tetanus/diphtheria vaccination, vaccine-specific intracellular IgG cells was observed in blood 8 days after vaccination, but no similar surge of IgA plasmablasts could be observed. This may indicate that there is independent regulation of systemic and mucosal humoral immune responses. ${ }^{68}$ Similarly, it was observed that following anti-CD20 (rituximab) therapy, IgA plasmablasts were still maintained in the blood and plasma cells could be identified in the gut lamina propria, suggesting that the B-cell precursors of these cells were not affected by the anti-CD20 therapy. ${ }^{69}$ Of note, the maintenance of plasma cells in the gut lamina propria could also be explained by some gut plasma cells having long lifespans (see below).

Evidence for disconnection of mucosal and systemic humoral responses, at least to some degree, has also been obtained by staining of $B$ cells and plasma cells with fluorescent virus-like particles of rotavirus. In a study of peripheral blood of healthy subjects, $0.6 \%$ of the B cells stained with rotavirus VP6 particles, but only about $10 \%$ of these cells carried the $\alpha 4 \beta 7$ guthoming receptor. ${ }^{70}$ The rotavirus-specific B cells had a bias in usage of $\mathrm{VH}$ gene segments when compared with random memory B cells or B cells of gut-homing phenotype, particularly not only VH1-46 but also VH4-31 and VH4-39. Among all gut-homing B cells, there was bias for VH4 gene family usage, particularly VH4-39. Interestingly, rotavirus-specific lamina propria plasma cells isolated with the same type of virus-like particles have a bias for VH4 usage, particularly VH4-39. ${ }^{17,20}$ These results, though not comprehensive, may suggest that the $\mathrm{VH}$ usage of B cells that later home to and operate in the gut as plasma cells is influenced not only by antigen but possibly also by the mucosal priming.

It has been suggested that the marginal zone B-cell subset that is normally resident in the spleen and that is responsible for systemic immune responses to bacterial polysaccharide antigens in humans may develop in GALT. ${ }^{71}$ Human splenic marginal zone B cells (unlike those in mice) have mutated IGHV genes suggestive of previous antigen encounter and their origin remains enigmatic. ${ }^{72}$ Consistent with a role for the gut in development of the systemic B-cell repertoire, Vossenkamper et al. ${ }^{73}$ observed that immature transitional type $2 \mathrm{~B}$ cells are present in GALT and that they are activated in this microenvironment. This study also described that B cells in most cases of the autoimmune disease systemic lupus erythematosus, which have been reported to be defective in mechanisms that regulate peripheral B-cell tolerance, ${ }^{74}$ are compromised in their ability to enter the gut through their reduced expression of $\alpha 4 \beta 7$ integrin. The significance of this and any possible link to the development of marginal zone B cells remains to be determined.

\section{ANTIBODY REPERTOIRE AND REACTIVITY OF GUT PLASMA CELLS}

The Ig repertoire of the human adult gut plasma cells is highly diverse with a high degree of somatic mutations. ${ }^{75,76}$ The number of somatic mutations increases with age, suggesting that cumulated antigen exposure contributes to accumulation of mutations over time. ${ }^{75,77}$ Interestingly, the degree of mutations is as high in plasma cells of the duodenum as of the colon despite the fact that bacterial colonization is scarce in the proximal gut. ${ }^{75}$ Dietary antigens are likely the major drivers for upper small bowel humoral responses. Thus, to explain this observation, either dietary antigens give rise to highly mutated responses or, alternatively, plasma cells originating from a B-cell clone could have wide distribution over the gut. Glutenspecific plasma cells in celiac disease have limited mutations of their antibody genes, ${ }^{78}$ and with the reservation that celiac disease response might not be representative of antibody responses to dietary antigens in general, this lends some credence to the latter explanation. In fact, this notion of widespread dissemination of plasma cells has received experimental support from many but not all studies. Early work employing complementarity-determining region-3 spectratyping and sequence analysis suggested clonal sharing between plasma cells in the small bowel and colon ${ }^{75}$ as well as between multiple distinct sites in the colon. ${ }^{79}$ Recent work by use of high-throughput Ig VH gene sequencing demonstrated substantial clonal sharing between plasma cells of distinct 
duodenal biopsies of celiac disease patients, most notable not only for transglutaminase 2-specific cells but also for non-transglutaminase 2 -specific cells. ${ }^{80}$ Contrary to these observations, Yuvaraj et al. ${ }^{81}$ by sequence analysis of $\operatorname{IgA}$ $\mathrm{VH}$ genes of ileal biopsies observed many clonally related sequences in one biopsy but not between different biopsies. The authors interpreted this finding to support the notion of local expansion of IgA precursor cells in the lamina propria and suggested that there could be a first wave of memory B cells originating in the GCs that seed into the lamina propria and that these cells then expand locally. In a related but distinct model, He et al. ${ }^{41}$ suggested that colon lamina propria B cells by the influence of enterocyte-produced APRIL in a T-cellindependent manner can switch from IgM to IgA2 and then differentiate locally to become plasma cells. In vitro experiments gave support for this model. However, phenotypic analysis of lamina propria B cells in situ provided little support for neither of these models. Boursier et al. ${ }^{82}$ observed no signs of local proliferation of $\mathrm{CD} 20^{+}$or $\mathrm{CD} 19^{+}$cells in the lamina propria and found no evidence of AID mRNA expression in lamina propria outside the organized GALT; the latter finding being consistent with more recent observations. ${ }^{80}$ Thus it appears that the majority of gut plasma cells are generated by GC reactions, giving CSR and somatic mutations, and afterwards the plasma cells are seeded into the lamina propria in wide areas of the gut.

Another useful source of information for understanding gut humoral immunity is sequencing in large scale of Ig heavy and light chain genes of single plasma cells and testing of the reactivity of reconstituted recombinant monoclonal antibodies. Benkert et al. ${ }^{16}$ sequenced IgA and IgG plasma cells from the terminal ileum of healthy subjects. They found that all antibodies, both IgA and IgG, had high numbers of somatic mutations. Again, evidence of clonal expansions was observed; about $4 \%$ of all IgA and $12 \%$ of all IgG antibodies were assigned to expanded clones, but clonally related B cells were not shared between the $\operatorname{IgA}^{+}$and $\mathrm{IgG}^{+}$plasma cell compartments. Despite some low level of crossreactivity with several bacterial species, and some degree of polyreactivity to self-antigens, both IgA and IgG plasma cells in general expressed antibodies that were highly specific. Specific reactivity of recombinant antibodies were also observed by isolation of rotavirus-specific plasma cells from healthy subjects ${ }^{17}$ as well as by transglutaminase 2 and gluten-specific plasma cells of celiac disease patients. ${ }^{78,80}$ Taken together, these results strongly indicate that gut plasma cells are generated in response to specific antigens, and they do not give support to a concept of the existence of scarcely mutated antibodies that have a broad reactivity, for instance, to commensal bacteria in general. It has been suggested that polyreactivity so often cited as a property of IgA could be a consequence of nonspecific binding through carbohydrate groups. ${ }^{83}$ This interesting field remains open to further investigation.

Ig heavy chains are expressed with either kappa or lambda light chains. Whereas the ratio of IgK:IgL for serum $\operatorname{IgG}$ is approximately 1.7:1, the figure for IgA is $1.2: 1{ }^{84}$ As discussed above, a bias toward expression of IgL is also seen in B cells expressing IgA, in particular, memory cells lacking CD27. ${ }^{34}$ It has been suggested that a movement of $B$ cells from the expression of kappa light chain to lambda light chain could occur by receptor revision where $B$ cells outside the bone marrow re-express RAG proteins that mediate secondary light chain gene rearrangements. Perhaps the best evidence for this is the bias toward the most $3^{\prime} \mathrm{J}$ segments in lambda excision circle by-products of the rearrangement process isolated from IgA plasma cells. ${ }^{85}$ Light chain drifting could be a mechanism that diversifies the antigen-binding repertoire of intestinal Igs alongside somatic hypermutation and could be a particular feature of $\mathrm{CD} 27^{-}$memory cells that may be independent of cognate interactions through CD $40 .^{34}$

\section{PERSISTENT GUT HUMORAL MEMORY: LONG-LIVED MEMORY B CELLS AND PLASMA CELLS}

Persistent humoral memory to gut pathogens and other gut antigens can be obtained by long-lived memory B cells replenishing dying plasma cells or by plasma cells that themselves are long-lived. The possibility of long-lived gut plasma cells was not considered until recently as an early study of mice established the notion that gut plasma cells are short lived with an average turnover of a few days with maximal lifespan of a few weeks. Staining of rotavirus-specific plasma cells in healthy individuals with no obvious recent history of rotavirus infection, however, gave an indication that there could be longevity among gut plasma cells. ${ }^{17,20}$ The fact that some but not all IgA and IgM plasma cells survive in biopsy cultures after 4 weeks without signs of proliferation supports the concept that there could not only be long-lived plasma cells in the gut but also cells with shorter lifespans. ${ }^{18}$ Gut plasma cells lack CD95 and have higher mRNA expression levels of $B c l-2$, Blimp-1, IRF-4, and XBP-1 than intestinal memory B cells, further indicating that the gut harbors long-lived plasma cells. ${ }^{20}$ Future studies are needed to establish whether there are distinct populations of plasma cells with regards to lifespans and also how long plasma cells survive in the gut.

The importance of memory $\mathrm{B}$ cells for gut humoral immunity has been extensively studied in the mouse and recently some relevant human studies have also appeared. High-throughput sequence analysis of Ig heavy chain genes of cells in colon biopsies from healthy human subjects obtained before the start of 4 days after and 46 days after cessation of antibiotic treatment revealed the same repertoire of expanded and non-expanded clusters of clonally related IgA sequences in all samples. Backed up by parallel studies in mice where memory B cells were seen to circulate between inductive compartments with clonal sharing of plasma cells in gut and mammary glands, this longitudinal persistence of clonally related B cells in the IgA repertoire, despite major changes in the microbiota, was taken to support the notion of a continuous diversification of memory $\mathrm{B}$ cells and this was considered a central element in the shaping of the gut humoral response. ${ }^{77}$ IgA plasma cells of duodenal biopsies of celiac disease patients not reactive to transglutaminase (i.e., covering most of the 


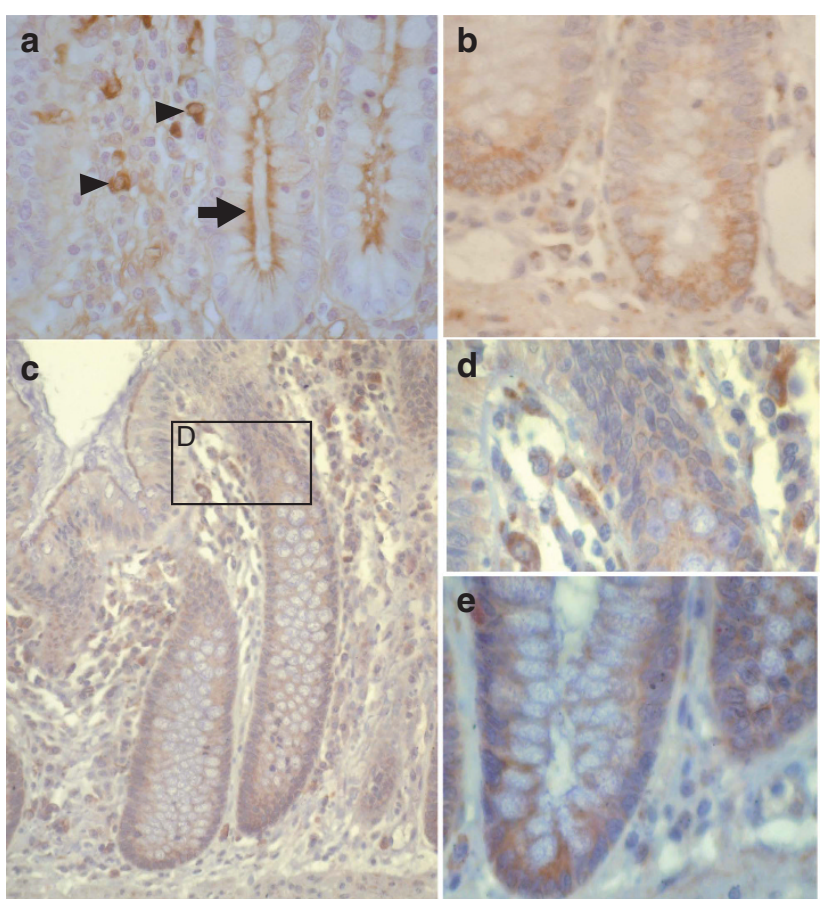

Figure 6 Paraffin sections of human ( $\mathbf{a}$ and $\mathbf{b}$ ) ileum and (c-e) colon stained for immunoglobulin A ( $\lg A)(a)$ and a proliferation-inducing ligand (APRIL; $\mathbf{b}-\mathbf{e}$ ). IgA plasma cells (arrow heads) secrete IgA that is transported into the gut lumen following binding to the polymeric immunoglobulin receptor (plgR) on the basolateral surface of epithelial cells. IgA in transit through epithelial cells is indicated with an arrow. In the small intestine, APRIL, like the plgR, is expressed mostly by epithelial cells in the bases of the crypts. In contrast, in the colon, APRIL is expressed by subepithelial macrophages (d; magnified area identified as box $D$ in $\mathbf{c}$ ) and epithelial cells (e). As in the ileum, epithelial APRIL is expressed mostly by crypt cells in the colon.

repertoire) on average have $10 \%$ related sequences among IgA $\mathrm{CD} 27^{+}$peripheral blood $\mathrm{B}$ cells also pointing to clonal relatedness between memory $\mathrm{B}$ cells and gut plasma cells. ${ }^{86}$ Based on available data, it hence seems likely that long-lived B-cell responses initiated in GCs do exist in humans, but the relative contribution of long-lived circulating memory B cells and long-lived plasma cells in the lamina propria to maintain a persistent gut humoral response awaits clarification.

\section{EXISTENCE OF PLASMA CELL SURVIVAL NICHES IN THE INTESTINE}

It is well established that in the bone marrow and in inflamed tissues there are plasma cells with very long lifespans. The maintenance of long-lived plasma cells in the bone marrow is dependent on plasma cells settling into survival niches made up of stromal cells and cytokines (reviewed in refs. 87, 88). Stromal cell expression of CD44 and the chemokine CXCL12 (binding CXCR4 on plasma cells) and the cytokines IL-6, tumor necrosis factor, APRIL, and B-cell activating factor (BAFF) (the two latter binding BCMA on plasma cells) are key components of such niches Figure 5e. There is competition for a finite number of survival niches and which cells make it into a niche is determined by stochastic processes and plasma cell intrinsic factors-their competence to compete. Having entered the niche, the plasma cells express high levels of the transcription factors Blimp-1, XBP-1, and IRF-4. Mouse studies have suggested that eosinophils producing APRIL are important for plasma cell survival in the bone marrow and for maintenance of IgA plasma cells in the gut, and presence of plasma cells adjacent to eosinophils in human intestine might suggest a similar role for eosinophils in man. ${ }^{89}$ (Figure 4) Interestingly, culturing of gut biopsies without tissue disruption gave the highest antibody production and plasma cell survival, indicating a role of the tissue environment also for gut plasma cell longevity. ${ }^{18}$ In these gut biopsy cultures, IL- 6 and APRIL were detected and blocking of the activity of endogenous APRIL and IL-6 with BCMA-Fc anti-human IL-6 antibody negatively affected antibody secretion, suggesting a role for these cytokines in gut plasma cell survival. By immunohistochemistry and quantitative real-time PCR, APRIL expression in the lamina propria was found in macrophages, dendritic cells, and neutrophils. ${ }^{23}$ Scarce or no expression of APRIL was seen in the areas of epithelium adjacent to gut lumen, but APRIL was intensely expressed by crypt epithelial cells (Figure 6). Likewise, mRNA for the APRIL receptors TACI and BCMA was detected in microdissected lamina propria tissue. By quantitative realtime PCR of lamina propria tissue devoid of lymphoid aggregates, expression of APRIL and BAFF was found in both fetal and adult samples and there was distinct expression of BCMA in adult samples and little expression of BAFF-R and TACI in both types of samples. ${ }^{24}$ By flow cytometric analysis of celiac disease biopsies, BCMA was expressed on most plasma cells, whereas BAFF-R and TACI were expressed only by a subgroup of cells and at variable levels. As for IL-6, this cytokine is produced by human small intestinal epithelial and smooth muscle cell lines in vitro and such cells could be sources for IL-6 in the intact intestinal tissue. ${ }^{90}$ Immunohistochemical analysis suggests that CXCL12 is constitutively expressed in the intestine by enterocytes but not by stromal cells, and it is upregulated upon inflammation. ${ }^{91}$ Taken together, it thus appears that many components of plasma cell survival niches as seen in the bone marrow exist in the gut (Figure 4).

\section{LESSONS FROM PATHOLOGY AND DISEASE}

Insight into the gut humoral immune system does not only come from studies of healthy subjects. Observations from patients with celiac disease in particular have given useful insights.

Celiac disease is characterized by highly disease-specific IgA and IgG antibodies to the autoantigen transglutaminase 2 (ref. 92) and deamidated gluten (gliadin) peptides. $^{93}$ Antitransglutaminase antibodies and probably also antideamidated gluten antibodies are only produced in individuals who express HLA-DQ2 and/or HLA-DQ8 upon gluten consumption. ${ }^{94}$ The levels of these antibodies in serum normalize within months after start-up of the gluten-free diet. ${ }^{95}$ The lesion localized in the proximal small intestine is characterized by blunting of intestinal villi and tissue leukocyte infiltration with a particularly striking increase in density of plasma cells. ${ }^{96}$ The strong 
disease association with certain HLA-DQ allotypes and diseasespecific antibodies demonstrating the same genetic restriction points to crosstalk between $\mathrm{T}$ cells and $\mathrm{B}$ cells being involved in the pathogenesis. ${ }^{97}$ Plasma cells specific for TG2 and deamidated gluten peptides can be isolated via staining with labeled antigen as they express surface Ig. On average, $10 \%$ of the plasma cells in the active celiac disease lesion are transglutaminase 2 specific, with less cells being specific for deamidated gluten. $^{78,80,86}$ The number of transglutaminase 2-specific plasma cells drops quickly after start-up of the gluten-free diet, but interestingly they do not disappear completely. ${ }^{98}$ There is high degree of clonal sharing of transglutaminase 2 -specific plasma cells between distinct duodenal biopsies, up to $70 \%$ as assessed by high-throughput sequencing of Ig $\mathrm{VH}$ genes, giving support to the notion of wide seeding of plasma cells in the small intestine. Moreover, there is poor correlation of density of IgA transglutaminase 2-specific plasma cells in the lesion and serum IgA anti-transglutaminase 2 antibody levels, suggesting that serum antibodies have a main source outside of the gut. ${ }^{98}$ Both the transglutaminase 2 - and the gluten-specific plasma cells have fewer mutations than other plasma cells in the lamina propria. The reason for this is unknown but may relate to these being extrafollicular responses or GC reactions of short duration. Access to GALT structures of celiac disease patients would help to dissect this, but ethical aspects represent clear restrictions on further research. The common low mutation rate of the responses to the two antigens could relate to common T-cell help; gluten-reactive and HLA-DQ2/DQ8restricted $\mathrm{T}$ cells could provide help to both transglutaminase 2 -specific and deamidated gluten-specific $B$ cells via transglutaminase-gluten peptide complexes. ${ }^{99}$ Likewise, B cells specific for the two antigens could serve as antigen-presenting cells for gluten-reactive T cells. Thus the abundance of transglutaminase 2- and deamidated gluten-specific plasma cells and the antibodies being good diagnostic markers for disease could be a reflection of $B$ cells having an important role as antigenpresenting cells amplifying the anti-gluten $\mathrm{T}$-cell response rather than the antibodies themselves having a pathogenic role. ${ }^{97}$

\section{OUTLOOK}

Despite substantial insight into the generation, dissemination, and regulation of the plasma cell population of the human gut, there is still much to be learned. Available evidence suggests that the repertoire of human gut IgA plasma cells is formed in response to specific recognition of antigens but under unique molecular control. With the arrival of high-throughput technologies that allow for analysis of B-cell receptor genes and transcriptional programs at the single-cell level even of cells specific for given antigens, it is to be expected that the near future will give interesting new knowledge of the human intestinal B-cell system. This should help us to make more efficient mucosal vaccines and to obtain a better understanding of gut immune disorders.

\section{ACKNOWLEDGMENTS}

This work was supported by grants from the European Commission (grant ERC-2010-Ad-268541), the Research Council of Norway (partially through its Centres of Excellence funding scheme, grant 179573/V40), and the South-East Norway Regional Health Authority (to L.M.S.) and Medical Research Council of Great Britain grant MR/L009382/1 (to J.S.). We thank Jorunn Stamnaes and Ramus Iversen for commenting on the manuscript.

\section{DISCLOSURE}

The author declared no conflict of interest.

2016 Society for Mucosal Immunology

\section{REFERENCES}

1. Brandtzaeg, P, Farstad, IN, Johansen, FE, Morton, HC, Norderhaug, IN \& Yamanaka, T. The B-cell system of human mucosae and exocrine glands. Immunol. Rev. 171, 45-87 (1999).

2. Palm, NW et al. Immunoglobulin A coating identifies colitogenic bacteria in inflammatory bowel disease. Cell 158, 1000-1010 (2014).

3. Turesson, I. Distribution of immunoglobulin-containing cells in human bone marrow and lymphoid tissues. Acta Med. Scand. 199, 293-304 (1976).

4. Baker, J \& Garrod, D. Epithelial cells retain junctions during mitosis. J. Cell Sci. 104, 415-425 (1993).

5. Dann, SM \& Eckmann, L. Innate immune defenses in the intestinal tract. Curr. Opin. Gastroenterol. 23, 115-120 (2007).

6. Wang, M, Gao, Z, Zhang, Z, Pan, L \& Zhang, Y. Roles of M cells in infection and mucosal vaccines. Hum. Vaccin. Immunother. 10, 3544-3551 (2014).

7. Cornes, JS. Number, size, and distribution of Peyer's patches in the human small intestine: Part I The development of Peyer's patches. Gut 6, 225-229 (1965).

8. Spencer, J, Finn, T, Pulford, KA, Mason, DY \& Isaacson, PG. The human gut contains a novel population of $B$ lymphocytes which resemble marginal zone cells. Clin. Exp. Immunol. 62, 607-612 (1985).

9. O'Leary, AD \& Sweeney, EC. Lymphoglandular complexes of the colon: structure and distribution. Histopathology 10, 267-283 (1986).

10. Bockman, DE \& Cooper, MD. Early lymphoepithelial relationships in human appendix. A combined light- and electron-microscopic study. Gastroenterology 68, 1160-1168 (1975).

11. Spencer, J, MacDonald, TT, Finn, T \& Isaacson, PG. The development of gut associated lymphoid tissue in the terminal ileum of fetal human intestine. Clin. Exp. Immunol. 64, 536-543 (1986).

12. Cornes, JS. Number, size, and distribution of Peyer's patches in the human small intestine: Part II The effect of age on Peyer's patches. Gut 6, 230-233 (1965).

13. Yamanaka, T, Straumfors, A, Morton, H, Fausa, O, Brandtzaeg, P \& Farstad, I. M cell pockets of human Peyer's patches are specialized extensions of germinal centers. Eur. J. Immunol. 31, 107-117 (2001).

14. Isaacson, PG \& Spencer, J. Malignant lymphoma of mucosa-associated lymphoid tissue. Histopathology 11, 445-462 (1987).

15. Farstad, IN, Carlsen, H, Morton, HC \& Brandtzaeg, P. Immunoglobulin A cell distribution in the human small intestine: phenotypic and functional characteristics. Immunology 101, 354-363 (2000).

16. Benckert, $\mathrm{J}$ et al. The majority of intestinal $\lg \mathrm{A}^{+}$and $\operatorname{lgG}{ }^{+}$plasmablasts in the human gut are antigen-specific. J. Clin. Invest. 121, 1946-1955 (2011).

17. Di Niro, R et al. Rapid generation of rotavirus-specific human monoclonal antibodies from small-intestinal mucosa. J. Immunol. 185, 5377-5383 (2010).

18. Mesin, L, Di Niro, R, Thompson, KM, Lundin, KE \& Sollid, LM. Long-lived plasma cells from human small intestine biopsies secrete immunoglobulins for many weeks in vitro. J. Immunol. 187, 2867-2874 (2011).

19. Pinto, $D$ et al. A functional $B C R$ in human IgA and IgM plasma cells. Blood 121, 4110-4114 (2013).

20. Nair, N et al. High-dimensional immune profiling of total and rotavirus VP6specific intestinal and circulating B cells by mass cytometry. Mucosal Immunol. 9, 68-82 (2016).

21. Dunn-Walters, DK, Isaacson, PG \& Spencer, J. Sequence analysis of human IgVH genes indicates that ileal lamina propria plasma cells are derived from Peyer's patches. Eur. J. Immunol. 27, 463-467 (1997).

22. Boursier, L, Dunn-Walters, DK \& Spencer, J. Characteristics of IgVH genes used by human intestinal plasma cells from childhood. Immunology 97 , 558-564 (1999). 
23. Barone, F, Patel, P, Sanderson, JD \& Spencer, J. Gut-associated lymphoid tissue contains the molecular machinery to support T-cell-dependent and T-cell-independent class switch recombination. Mucosal Immunol. 2, 495-503 (2009).

24. Gustafson, CE et al. Limited expression of APRIL and its receptors prior to intestinal IgA plasma cell development during human infancy. Mucosal Immunol. 7, 467-477 (2014).

25. Weill, JC, Weller, S \& Reynaud, CA. Human marginal zone B cells. Annu. Rev. Immunol. 27, 267-285 (2009).

26. Falini, B et al. Expression of the IRTA1 receptor identifies intraepithelial and subepithelial marginal zone B cells of the mucosa-associated lymphoid tissue (MALT). Blood 102, 3684-3692 (2003).

27. Hatzivassiliou, Get al. IRTA1 and IRTA2, novel immunoglobulin superfamily receptors expressed in $\mathrm{B}$ cells and involved in chromosome 1q21 abnormalities in B cell malignancy. Immunity 14, 277-289 (2001).

28. Ehrhardt, GR, Davis, RS, Hsu, JT, Leu, CM, Ehrhardt, A \& Cooper, MD. The inhibitory potential of Fc receptor homolog 4 on memory B cells. Proc. Natl. Acad. Sci. USA 100, 13489-13494 (2003).

29. Ehrhardt, GR et al. Expression of the immunoregulatory molecule FcRH4 defines a distinctive tissue-based population of memory B cells. J. Exp. Med. 202, 783-791 (2005).

30. Sohn, HW, Krueger, PD, Davis, RS \& Pierce, SK. FcRL4 acts as an adaptive to innate molecular switch dampening BCR signaling and enhancing TLR signaling. Blood 118, 6332-6341 (2011).

31. Moir, $\mathrm{S}$ et al. Evidence for HIV-associated $\mathrm{B}$ cell exhaustion in a dysfunctional memory B cell compartment in HIV-infected viremic individuals. J. Exp. Med. 205, 1797-1805 (2008).

32. Weiss, GE et al. Atypical memory B cells are greatly expanded in individuals living in a malaria-endemic area. J. Immunol. 183 (3), 2176-2182 (2009).

33. Yeo, $L$ et al. Expression of FCRL4 defines a pro-inflammatory, RANKLproducing B cell subset in rheumatoid arthritis. Ann. Rheum. Dis. 74, 928935 (2015).

34. Berkowska, MA et al. Human memory B cells originate from three distinct germinal center-dependent and -independent maturation pathways. Blood 118, 2150-2158 (2011).

35. Cagigi, A et al. CD27(-) B-cells produce class switched and somatically hyper-mutated antibodies during chronic HIV-1 infection. PLoS One 4, e5427 (2009).

36. Berkowska, MA et al. irculating human CD27-lgA ${ }^{+}$memory B cells recognize bacteria with polyreactive Igs. J. Immunol. 195, 1417-1426 (2015).

37. Wu, YC, Kipling, D \& Dunn-Walters, DK. The relationship between CD27 negative and positive B cell populations in human peripheral blood. Front. Immunol. 2, 81 (2011).

38. Litinskiy, MB et al. DCs induce CD40-independent immunoglobulin class switching through BLyS and APRIL. Nat. Immunol. 3, 822-829 (2002).

39. Facchetti, F, Appiani, C, Salvi, L, Levy, J \& Notarangelo, LD. Immunohistologic analysis of ineffective CD40-CD40 ligand interaction in lymphoid tissues from patients with X-linked immunodeficiency with hyper-lgM. Abortive germinal center cell reaction and severe depletion of follicular dendritic cells. J. Immunol. 154, 6624-6633 (1995).

40. Cerutti, A et al. CD40 ligand and appropriate cytokines induce switching to $\operatorname{lgG}$, IgA, and IgE and coordinated germinal center and plasmacytoid phenotypic differentiation in a human monoclonal $\operatorname{lgM}^{+} \operatorname{lgD}{ }^{+} B$ cell line. J. Immunol. 160, 2145-2157 (1998).

41. He, B et al. Intestinal bacteria trigger T cell-independent immunoglobulin A(2) class switching by inducing epithelial-cell secretion of the cytokine APRIL. Immunity 26, 812-826 (2007).

42. Almejun, MB et al. Naturally occurring mutation affecting the MyD88binding site of TNFRSF13B impairs triggering of class switch recombination. Eur. J. Immunol. 43, 805-814 (2013).

43. van Vlasselaer, P, Punnonen, J \& de Vries, JE Transforming growth factorbeta directs IgA switching in human B cells. J. Immunol. 148, 2062-2067 (1992).

44. Avery, DT, Bryant, VL, Ma, CS, de Waal Malefyt, R \& Tangye, SG IL-21induced isotype switching to $\lg G$ and $\lg A$ by human naive $B$ cells is differentially regulated by IL-4. J. Immunol. 181, 1767-1779 (2008).

45. Seo, GY et al. Retinoic acid acts as a selective human IgA switch factor. Hum. Immunol. 75, 923-929 (2014).
46. Fayette, $J$ et al. Human dendritic cells skew isotype switching of CD40activated naive B cells towards IgA1 and IgA2. J. Exp. Med. 185, 1909-1918 (1997).

47. Endsley, MA et al. Human IgA-inducing protein from dendritic cells induces IgA production by naive lgD+ B cells. J. Immunol. 182, 1854-1859 (2009).

48. Lin, M, Du, L, Brandtzaeg, P \& Pan-Hammarstrom, Q. IgA subclass switch recombination in human mucosal and systemic immune compartments. Mucosal Immunol. 7, 511-520 (2014).

49. Kett, K, Baklien, K, Bakken, A, Kral, JG, Fausa, O \& Brandtzaeg, P. Intestinal B-cell isotype response in relation to local bacterial load: evidence for immunoglobulin A subclass adaptation. Gastroenterology 109, 819-825 (1995).

50. Brandtzaeg, P. Presence of $J$ chain in human immunocytes containing various immunoglobulin classes. Nature 252, 418-420 (1974).

51. Mestecky, J, Schrohenloher, RE, Kulhavy, R, Wright, GP \& Tomana, M. Site of $\mathrm{J}$ chain attachment to human polymeric IgA. Proc. Natl. Acad. Sci. USA 71, 544-548 (1974).

52. Garcia-Pardo, A, Lamm, ME, Plaut, AG \& Frangione, B. $J$ chain is covalently bound to both monomer subunits in human secretory IgA. J. Biol. Chem. 256, 11734-11738 (1981).

53. Inman, FP \& Ricardo, MJ Jr. The association of $J$ chain with the Fc region of human IgM. J. Immunol. 112, 229-233 (1974).

54. Brandtzaeg, P. Complex formation between secretory component and human immunoglobulins related to their content of $J$ chain. Scand. J. Immunol. 5, 411-419 (1976).

55. Brandtzaeg, $P$ \& Prydz, $H$. Direct evidence for an integrated function of $J$ chain and secretory component in epithelial transport of immunoglobulins. Nature 311, 71-73 (1984).

56. Brandtzaeg, P. Role of $\mathrm{J}$ chain and secretory component in receptormediated glandular and hepatic transport of immunoglobulins in man. Scand. J. Immunol. 22, 111-146 (1985).

57. Kaetzel, CS, Robinson, JK, Chintalacharuvu, KR, Vaerman, JP \& Lamm, ME. The polymeric immunoglobulin receptor (secretory component) mediates transport of immune complexes across epithelial cells: a local defense function for IgA. Proc. Natl. Acad. Sci. USA 88, 8796-8800 (1991).

58. Fernandez, MI, Pedron, T, Tournebize, R, Olivo-Marin, JC, Sansonetti, PJ \& Phalipon, A. Anti-inflammatory role for intracellular dimeric immunoglobulin a by neutralization of lipopolysaccharide in epithelial cells. Immunity $\mathbf{1 8 ,}$ 739-749 (2003).

59. Moura, IC et al. Identification of the transferrin receptor as a novel immunoglobulin (Ig)A1 receptor and its enhanced expression on mesangial cells in IgA nephropathy. J. Exp. Med. 194, 417-425 (2001).

60. Matysiak-Budnik, Tet al. Secretory IgA mediates retrotranscytosis of intact gliadin peptides via the transferrin receptor in celiac disease. J. Exp. Med. 205, 143-154 (2008).

61. Brandtzaeg, P. Function of mucosa-associated lymphoid tissue in antibody formation. Immunol. Invest. 39, 303-355 (2010).

62. Mora, JR et al. Generation of gut-homing IgA-secreting B cells by intestinal dendritic cells. Science 314, 1157-1160 (2006).

63. Shirakawa, AK, Nagakubo, D, Hieshima, K, Nakayama, T, Jin, Z \& Yoshie, O. 1,25-dihydroxyvitamin D3 induces CCR10 expression in terminally differentiating human B cells. J. Immunol. 180, 2786-2795 (2008).

64. Quiding-Jarbrink, $M$ et al. Differential expression of tissue-specific adhesion molecules on human circulating antibody-forming cells after systemic, enteric, and nasal immunizations. A molecular basis for the compartmentalization of effector B cell responses. J. Clin. Invest. 99, 1281-1286 (1997).

65. Sundstrom, P, Lundin, SB, Nilsson, LA \& Quiding-Jarbrink, M. Human IgA-secreting cells induced by intestinal, but not systemic, immunization respond to CCL25 (TECK) and CCL28 (MEC). Eur. J. Immunol. 38, 3327-3338 (2008).

66. Spencer, J, Hussell, T, Mustafa, Y \& Perry, ME. Immunohistochemical and ultrastructural analysis of an extracellular matrix bound antigen preferentially associated with mucosal postcapillary venules. J. Anat. 189, 335-340 (1996).

67. Salmi, M \& Jalkanen, S. Lymphocyte homing to the gut: attraction, adhesion, and commitment. Immunol. Rev. 206, 100-113 (2005).

68. Mei, HE et al. Blood-borne human plasma cells in steady state are derived from mucosal immune responses. Blood 113, 2461-2469 (2009). 
69. Mei, HE et al. Steady-state generation of mucosal $\lg \mathrm{A}^{+}$plasmablasts is not abrogated by B-cell depletion therapy with rituximab. Blood 116, 5181-5190 (2010).

70. Weitkamp, JH, Kallewaard, NL, Bowen, AL, Lafleur, BJ, Greenberg, HB \& Crowe, JE Jr. VH1-46 is the dominant immunoglobulin heavy chain gene segment in rotavirus-specific memory B cells expressing the intestinal homing receptor $\alpha 4 \beta 7$. J. Immunol. 174, 3454-3460 (2005).

71. Tarlinton, D. Sheepish B cells: evidence for antigen-independent antibody diversification in humans and mice. J. Exp. Med. 205, 1251-1254 (2008).

72. Dunn-Walters, DK, Isaacson, PG \& Spencer, J. Analysis of mutations in immunoglobulin heavy chain variable region genes of microdissected marginal zone (MGZ) B cells suggests that the MGZ of human spleen is a reservoir of memory B cells. J. Exp. Med. 182, 559-566 (1995).

73. Vossenkamper, Aet al. A role for gut-associated lymphoid tissue in shaping the human B cell repertoire. J. Exp. Med. 210, 1665-1674 (2013).

74. Yurasov, S et al. Defective B cell tolerance checkpoints in systemic lupus erythematosus. J. Exp. Med. 201, 703-711 (2005).

75. Dunn-Walters, DK, Boursier, L \& Spencer, J Hypermutation, diversity and dissemination of human intestinal lamina propria plasma cells. Eur. J. Immunol. 27, 2959-2964 (1997).

76. Fischer, M \& Kuppers, R. Human IgA- and IgM-secreting intestinal plasma cells carry heavily mutated $\mathrm{VH}$ region genes. Eur. J. Immunol. 28, 2971-2977 (1998).

77. Lindner, $\mathrm{C}$ et al. Diversification of memory B cells drives the continuous adaptation of secretory antibodies to gut microbiota. Nat. Immunol. 16 880-888 (2015).

78. Steinsbo, O et al. Restricted VH/VL usage and limited mutations in glutenspecific IgA of coeliac disease lesion plasma cells. Nat. Commun. 5, 4041 (2014).

79. Holtmeier, W, Hennemann, A \& Caspary, WF IgA and IgM V(H) cin human colon: evidence for clonally expanded B cells that are widely disseminated. Gastroenterology 119, 1253-1266 (2000).

80. Di Niro, Ret al. High abundance of plasma cells secreting transglutaminase 2-specific IgA autoantibodies with limited somatic hypermutation in celiac disease intestinal lesions. Nat. Med. 18, 441-445 (2012).

81. Yuvaraj, S et al. Evidence for local expansion of IgA plasma cell precursors in human ileum. J. Immunol. 183, 4871-4878 (2009).

82. Boursier, L, Gordon, JN, Thiagamoorthy, S, Edgeworth, JD \& Spencer, J. Human intestinal IgA response is generated in the organized gutassociated lymphoid tissue but not in the lamina propria. Gastroenterology 128, 1879-1889 (2005).

83. Pabst, O. New concepts in the generation and functions of IgA. Nat. Rev. Immunol. 12, 821-832 (2012).
84. Koulieris, E et al. Ratio of involved/uninvolved immunoglobulin quantification by Hevylite assay: clinical and prognostic impact in multiple myeloma. Exp. Hematol. Oncol. 1, 9 (2012).

85. Su, $W$ et al. Lambda light chain revision in the human intestinal IgA response. J. Immunol. 181, 1264-1271 (2008).

86. Snir, O, Mesin, L, Gidoni, M, Lundin, KE, Yaari, G \& Sollid, LM. Analysis of celiac disease autoreactive gut plasma cells and their corresponding memory compartment in peripheral blood using high-throughput sequencing. J. Immunol. 194, 5703-5712 (2015).

87. Radbruch, A et al. Competence and competition: the challenge of becoming a long-lived plasma cell. Nat. Rev. Immunol. 6, 741-750 (2006).

88. Nutt, SL, Hodgkin, PD, Tarlinton, DM \& Corcoran, LM. The generation of antibody-secreting plasma cells. Nat. Rev. Immunol. 15, 160-171 (2015).

89. Chu, VT et al. Eosinophils promote generation and maintenance of immunoglobulin-A-expressing plasma cells and contribute to gut immune homeostasis. Immunity 40, 582-593 (2014).

90. Ng, EKet al. Human intestinal epithelial and smooth muscle cells are potent producers of IL-6. Mediators Inflamm. 12, 3-8 (2003).

91. Dotan, I et al. CXCL12 is a constitutive and inflammatory chemokine in the intestinal immune system. Inflamm. Bowel Dis. 16, 583-592 (2010).

92. Dieterich, $W$ et al. Identification of tissue transglutaminase as the autoantigen of celiac disease. Nat. Med. 3, 797-801 (1997).

93. Osman, AA et al. B cell epitopes of gliadin. Clin. Exp. Immunol. 121, 248-254 (2000).

94. Bjorck, S, Brundin, C, Lorinc, E, Lynch, KF \&Agardh, D. Screening detects a high proportion of celiac disease in young HLA-genotyped children. J. Pediatr. Gastroenterol. Nutr. 50, 49-53 (2010).

95. Lund, F et al. Decrease by $50 \%$ of plasma IgA tissue transglutaminase antibody concentrations within 2 months after start of gluten-free diet in children with celiac disease used as a confirming diagnostic test. Scand. J. Clin. Lab. Invest. 76, 128-132 (2016).

96. Baklien, K, Brandtzaeg, P \& Fausa, O. Immunoglobulins in jejunal mucosa and serum from patients with adult coeliac disease. Scand. J. Gastroenterol. 12, 149-159 (1977).

97. Stamnaes, J \& Sollid, LM. Celiac disease: autoimmunity in response to food antigen. Semin. Immunol. 27, 343-352 (2015).

98. Di Niro, Ret al. Responsive population dynamics and wide seeding into the duodenal lamina propria of transglutaminase-2-specific plasma cells in celiac disease. Mucosal Immunol. 9, 254-264 (2016).

99. Sollid, LM, Molberg, O, McAdam, S \& Lundin, KE. Autoantibodies in coeliac disease: tissue transglutaminase-guilt by association?. Gut 41, 851-852 (1997). 